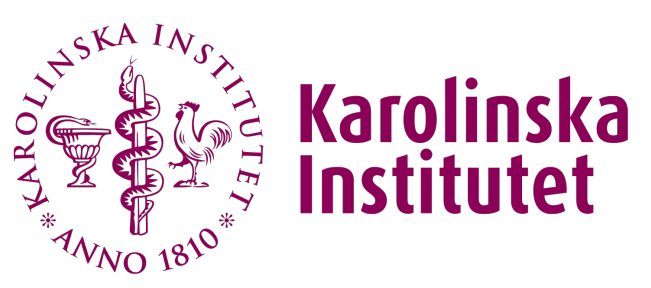

Karolinska Institutet

http://openarchive.ki.se

This is a Peer Reviewed Accepted version of the following article, accepted for publication in Cancer Immunology Immunotherapy.

\title{
A novel inhibitor of proteasome deubiquitinating activity renders tumor cells sensitive to TRAIL-mediated apoptosis by natural killer cells and T cells
}

Sarhan, Dhifaf; Wennerberg, Erik; D'Arcy, Pádraig; Gurajada, Deepthy; Linder, Stig; Lundqvist, Andreas

Cancer Immunol Immunother. 2013 Aug;62(8):1359-68.

http://doi.org/10.1007/s00262-013-1439-1

http://hdl.handle.net/10616/41578

If not otherwise stated by the Publisher's Terms and conditions, the manuscript is deposited under the terms of the Creative Commons Attribution-NonCommercial-NoDerivatives License (http://creativecommons.org/licenses/by-nc-nd/4.0/), which permits non-commercial re-use, distribution, and reproduction in any medium, provided the original work is properly cited, and is not altered, transformed, or built upon in any way. 


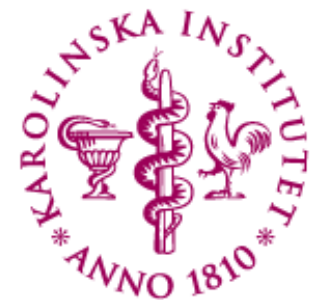 \\ Karolinska Institutet}

This is an author produced version of a paper accepted by Cancer Immunology Immunotherapy. This paper has been peer-reviewed but does not include the final publisher proofcorrections or journal pagination.

Cancer Immunol Immunother. 2013 May 21. [Epub ahead of print]

A novel inhibitor of proteasome deubiquitinating activity renders tumor cells sensitive to TRAIL-mediated apoptosis by natural killer cells and $\mathrm{T}$ cells

Sarhan, Dhifaf; Wennerberg, Erik; D'Arcy, Padraig;

Gurajada, Deepthy; Linder, Stig; Lundqvist, Andreas

URL: http://dx.doi.org/10.1007/s00262-013-1439-1

Access to the published version may require subscription.

Published with permission from: Springer 


\title{
A novel inhibitor of proteasome deubiquitinating activity renders tumor cells sensitive to TRAIL-mediated apoptosis by natural killer cells and T cells
}

Dhifaf Sarhan*, Erik Wennerberg*, Padraig D’Arcy*, Deepthy Gurajada*, Stig Linder* and Andreas Lundqvist*

*Karolinska Institutet, Department of Oncology-Pathology, Cancer Center Karolinska, Stockholm, Sweden

Address for correspondence: Andreas Lundqvist, $\mathrm{PhD}$. Karolinska Institutet, Department of Oncology-Pathology, Cancer Center Karolinska R8:01, 17176 Stockholm, Sweden. Phone: +46851776859; Fax: +468309195. Email: andreas.lundqvist@ki.se

\begin{abstract}
The proteasome inhibitor bortezomib simultaneously renders tumor cells sensitive to killing by natural killer (NK) cells and resistant to killing by tumor-specific T cells. Here, we show that b-AP15, a novel inhibitor of proteasome deubiquitinating activity, sensitizes tumors to both NK and T cell-mediated killing. Exposure to b-AP15 significantly increased the susceptibility of tumor cell lines of various origins to NK $(\mathrm{p}<0.0002)$ and T cell $(\mathrm{p}=0.02)-$ mediated cytotoxicity. Treatment with b-AP15 resulted in increased TRAIL [tumor necrosis factor-related apoptosis-inducing ligand] receptor-2 expression $(\mathrm{p}=0.03)$ and decreased cFLIP expression in tumor cells in vitro. In tumor-bearing SCID/Beige mice, treatment with b-AP15 followed by infusion of either human NK cells or tumor-specific T cells resulted in a significantly delayed tumor progression compared with mice treated with NK cells $(p=0.006)$, T cells $(\mathrm{p}<0.0001)$, or $\mathrm{b}-\mathrm{AP} 15$ alone $(\mathrm{p}=0.003)$. Combined infusion of NK and T cells in tumor-bearing BALB/c mice following treatment with b-AP15 resulted in a significantly prolonged long-term survival compared with mice treated with b-AP15 and NK or T cells $(\mathrm{p} \leq 0.01)$. Our findings show that $\mathrm{b}-\mathrm{AP} 15$-induced sensitization to TRAIL-mediated apoptosis could be used as a novel strategy to augment the anti-cancer effects of adoptively infused NK and $\mathrm{T}$ cells in patients with cancer.
\end{abstract}

Keywords: Natural killer cells, T cells, proteasome inhibitor, TRAIL, Immunotherapy 
Précis: Treatment with the proteasome deubiquitinating inhibitor b-AP15 sensitizes tumor cells to NK and $\mathrm{T}$ cell -mediated killing in vitro and in vivo. Infusion of both $\mathrm{NK}$ and $\mathrm{T}$ cells following b-AP15 treatment prolongs survival in tumor-bearing hosts.

\section{Introduction}

Adoptive $\mathrm{T}$ cell therapy elicits long-lasting clinical responses in patients with malignant metastatic melanoma [1]. However, randomized clinical trials have failed to find similar results in other malignancies [2]. In addition the adoptive infusion of autologous natural killer (NK) cells has yet to show clinical benefit in treating cancer patients [3]. This clinical failure may be in part due to sustained immunological selection pressure on tumor cells resulting in the development of tumor escape variants that are effectively invisible to the immune system. One of the most frequent immune escape strategies tumors use to avoid being detected by cytotoxic T cells is down-regulation of MHC class I [4,5]. As a result, individual cells may display differential expression of MHC class I within a growing tumor mass [6]. While MHC class I positive tumor cells are targeted by tumor-specific T cells, MHC class I negative tumor cells can be killed by NK cells due to lack of ligation of inhibitory Killer Immunoglobulinlike receptors (KIRs) on NK cells. Simultaneous adoptive cell therapy with tumor-specific T cells and NK cells may therefore offer a strategy to generate broader anti-tumor responses compared with infusion of NK or T cells as a monotherapy. Such combined therapy could potentially result in improved clinical responses.

Besides secreting lytic granules, T and NK cells ligate death receptors on tumor cells to induce apoptosis [7-10]. We and others have recently demonstrated that exposure to the proteasome inhibitor bortezomib significantly up-regulated the expression of death receptors to TNF-related apoptosis-inducing ligand (TRAIL) [11-13]. However, bortezomib-treated tumors sensitized to NK cell apoptosis simultaneously acquire resistance to antigen-specific T cells [14]. As bortezomib predominantly inhibits the chymotryptic-like activity of the 20S 
proteasome [15], impaired antigen processing and presentation prevent tumor-specific $\mathrm{T}$ cells from killing bortezomib-treated tumors.

We have recently identified the small molecule b-AP15 as a novel inhibitor of proteasome deubiquitinating activity [16]. Cells treated with b-AP15 accumulate polyubiquitinated proteins, with similar kinetics to cells treated with bortezomib. b-AP15-induced proteasome inhibition was concomitant with the up-regulation of apoptotic markers and the accumulation of cell-cycle regulatory proteins, leading to cell cycle arrest and apoptosis independent of the tumor suppressor p53 or overexpression of the $B C L 2$ oncogene, which are implicated in bortezomib resistance.

In the present study we sought to investigate whether inhibition of proteasome deubiquitinating activity sensitizes tumors to both T and NK cell-mediated killing. Similarly to bortezomib, we found that treatment with sub-apoptotic doses of b-AP15 resulted in an increased surface expression of TRAIL-R2 and decreased expression of cFLIP in tumor cells. As a consequence, b-AP15-treated tumors displayed an increased sensitivity to killing by both $\mathrm{NK}$ and T cells in vitro. Furthermore, significantly increased survival times were observed in mice treated with b-AP15 followed by combined infusion of syngeneic NK and tumorspecific T cells relative to mice treated with b-AP15 followed by infusion of either syngeneic NK or tumor-specific T cells. 


\section{Materials and methods}

\section{Human NK and T cell culture}

Human NK cells were isolated from peripheral blood mononuclear cells (PBMC) of healthy donors and melanoma patients (ethical permit dnr \#2009/848-3) by negative immunomagnetic bead depletion (Miltenyi Biotech, BergischGladbach, Germany). Purified NK cells ( $\geq 95 \%$ ) were expanded with 25 Gy irradiated autologous PBMC (feeder cells) at a 1:20 cell ratio (NK: feeder) in X-VIVO 20 media (Lonza, Verviers, Belgium) supplemented with 10\% heat-inactivated human AB serum (Karolinska Hospital, Stockholm, Sweden) and 500 U/ml recombinant human interleukin-2 (IL-2) (Novartis pharma GmbH, Nurnberg, Germany). Fresh medium containing $500 \mathrm{U} / \mathrm{ml} \mathrm{IL-2} \mathrm{was} \mathrm{added} \mathrm{on} \mathrm{days} \mathrm{5,} 8$ and 11, and NK cells were tested for cytotoxicity or infused into mice on days 11-14 of expansion. Contamination of CD3 positive T cells was $<1 \%$.

Tumor specific $\mathrm{T}$ cells were isolated from tumor biopsies from HLA-A2 positive melanoma patients. Biopsies were manually dissected into small pieces and transferred to 24-well plates followed by incubation with $6,000 \mathrm{U} / \mathrm{ml}$ of IL-2 in X-vivo 20 medium supplemented with 5\% AB serum for six days. Tumor infiltrating lymphocytes were screened for antigen-specificity by intracellular staining for interferon-gamma (IFN $\gamma$ ) and IL-2 (Biolegend, San Diego, USA) against T2 cells pulsed with HLA-A2 binding melanoma-associated peptides gp100, MAGE1, MAGE-3, Survivin and Mart-1 (Genecust, Dudelang, Luxembourg). 8.4\% of T cells

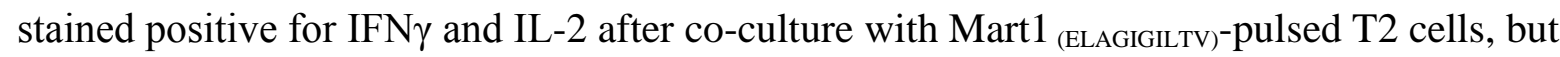
not against any of the other peptides. These TILs were expanded in X-vivo 20 medium supplemented with 5\% AB, $500 \mathrm{U} / \mathrm{ml} \mathrm{IL-2}$ and $50 \mathrm{ng} / \mathrm{ml}$ anti-CD3 antibody (Janssen-Cilag, Sollentuna, Sweden) and irradiated (40 Gy) allogeneic PBMC. Medium supplemented with $500 \mathrm{U} / \mathrm{ml}$ of IL-2 was replenished on days 5 and 8 of culture. Purity of CD3 positive T cells 
was $\geq 94 \%$ with $<1 \%$ contamination of CD56 positive NK cells. Expanded NK and T cells were tested against K562 cells (Supplementary Fig. 1A). T cells were tested negative against the HLA-A2 negative tumor cell line EST115 (Table 1).

\section{Murine NK and T cell culture}

Murine NK cells were isolated from BALB/c splenocytes by negative bead depletion (MACS, Miltenyi Biotech) and cultured in 96-U bottom plates in RPMI1640 medium supplemented with $10 \%$ FCS, $50 \mu \mathrm{M}$ Beta-mercapethanol, $25 \mathrm{ug} / \mathrm{ml}$ gentamycin, $2 \mathrm{mM}$ L-glutamine, $1 \%$ NEAA (Invitrogen, Eugene, Oregon, USA) and $500 \mathrm{U} / \mathrm{ml}$ of human IL-2 for 5 days. Murine tumor-specific T cells were generated by whole tumor cell vaccination. Briefly, BALB/c mice received three weekly intraperitoneal (i.p) injections of $1 \times 10^{6}$ irradiated (10,000 Rad) D2F2 breast cancer cells. Spleen and lymphnodes were collected and re-stimulated with irradiated $(5,000 \mathrm{Rad}) \mathrm{D} 2 \mathrm{~F} 2$ and recombinant human $\mathrm{IL}-2(100 \mathrm{U} / \mathrm{ml})$ in vitro for four days. T cells were tested for tumor reactivity in a 51Cr-release assay against D2F2 cells, YAC-1 cells, and RENCA cells. Generated T cells tested negative against RENCA (Table 1) and YAC-1 tumors (Supplementary Fig. 1B).

\section{Tumor cell lines}

Tumor cell lines include: EST152, EST027, EST066, EST049, EST025, JuSo (human melanoma) MDA453, MCF-7, MDA484 (human breast cancer), PC3, DU145 (human prostate cancer), J82, RT4 (human bladder cancer), A498, JOHW (kidney cancer), HCT116 (colon cancer), SKOV3, HeLa (ovarian cancer), BJ1 (normal fibroblast), and K562. Murine cell lines include: D2F2 (breast cancer), RENCA (renal cancer), B16 (melanoma) and YAC-1 (lymphoma). STR Identifier (Applied Biosystems, UK) was used to verify the origin of human tumor cell lines; EST152, EST027, EST066, EST049, EST025, MDA453, MCF-7, MDA484, J82, HCT116, HeLa and SKOV3. The EST melanoma cell lines were provided by 
Dr. Rolf Kiessling, Karolinska Institutet through the IPD-ESTDAB Database

(http://www.ebi.ac.uk/ipd/estdab/directory.html). All cell lines were maintained in RPMI1640 media with $10 \%$ fetal calf serum (Invitrogen, Eugene, Oregon, USA), $50 \mathrm{U} / \mathrm{ml}$ penicillin, and $50 \mathrm{mg} / \mathrm{ml}$ streptomycin (Invitrogen).

\section{Reagents and antibodies}

Tumor cells were treated in vitro with $1 \mu \mathrm{M}$ of b-AP15 (3,5-bis[(4-nitrophenyl)methylidene]1-prop-2-enoylpiperidin-4-one, Oncotargeting AB Uppsala, Sweden) for 3 hours before analysis for phenotype by flow cytometry or susceptibility to killing in cytotoxicity assays. J82 and EST027 cells were treated with 20 nM of bortezomib (Millennium Pharmaceuticals, Inc.) for 20 hours before testing in cytotoxicity assays. To evaluate TRAIL- or Fas ligand mediated cytotoxicity of human tumors, recombinant TRAIL or Fas ligand (Peprotech, London, UK) was added to cells in cytotoxicity assays at $100 \mathrm{ng} / \mathrm{ml}$ and $150 \mathrm{ng} / \mathrm{ml}$ respectively. Concanamycin A (CMA; Sigma, Schnelldorf, Germany) was added in cytotoxicity assays at $100 \mathrm{nM}$ to degrade perforin. Isolated and expanded NK cells and TILs were assessed for purity and TRAIL expression by flow cytometry after staining with antibodies against human CD3, CD56, CD4 and CD8, TRAIL (Biolegend). Human tumors were stained for TRAIL-R1, R2, R3, Fas, MICA/B and Nectin-2, MHC class I (Biolegend). Murine BALB/c D2F2 tumor cells were stained with TRAIL-R2 (Biolegend) before and after treatment with $1 \mu \mathrm{M}$ b-AP15 for 3 hours. Apoptosis was analyzed by staining with Annexin$\mathrm{V}$ and 7-AAD (Biolegend). All flow cytometry experiments were acquired on an LSRII (BD Biosciences, San Jose, California, USA) and data was analyzed using FlowJo software (Tree Star, Ashland, USA).

\section{Western Blot}


J82, JOHW, DU145, JuSo, A498, HCT116, HeLa and MCF-7 cells were treated with $1 \mu \mathrm{M}$ of b-AP15 for 3 hours or left untreated. Post-treatment cells were lysed in buffer (cellLytic M, Sigma, St. Louis, Mo, USA) containing protease inhibitor cocktail (Sigma). Equal amount of protein $(20 \mu \mathrm{g})$ from total cell lysates were resolved on NuPAGE gels, transferred to PVDF, blocked in 5\% milk and incubated overnight incubation with rabbit anti-c-FLIP (Cell Signaling Technology, Beverly, MA), or mouse anti- $\beta$-actin (Sigma) antibodies. Membranes were incubated with HRP-linked goat anti-rabbit or anti-mouse IgG Abs (Cell Signaling Technology) for 1 hour at room temperature and developed by enhanced chemiluminescence (GE Healthcare, Fairfield, CT). The protein quantity was determined relative to $\beta$-actin and analyzed by ImageJ-software (National Institutes of Health, http://rsb.info.nih.gov/ij).

\section{Cytotoxicity and cytokine production assays}

In chromium51-release cytotoxicity assays, target cells were labeled with $51 \mathrm{Cr}(50 \mu \mathrm{Ci})$ (PerkinElmer, Groningen, The Netherlands) and seeded in 96 U-bottom plates in triplicates. Human or murine NK or T cells were added to target cells at different E:T ratios. Following 18 hour incubation, $25 \mu \mathrm{l}$ of supernatant was transferred onto Luma plates (PerkinElmer) and analyzed using MicroBeta scintillation (TRILUX 1450) counter (PerkinElmer). For intracellular staining of IFN $\gamma, 10,000$ tumor cells were plated with 20,000-200,000 NK or T cells in a 96 U-bottom plate and incubated for 6 hours. Staining was performed following the manufacturer's instructions (BD Biosciences). Where indicated, cytotoxicity assays were performed in presence of neutralizing antibodies against TRAIL (10 ug/ml), NKG2D (10 ug/ml), Fas-ligand (10 ug/ml), DNAM-1(10 ug/ml) (Biolegend) or CMA (100 nM,).

\section{In vivo tumor models}

All animal experiments were performed at the Department of Microbiology, Tumor and Cell Biology (MTC) or the Swedish Institute for Infectious Disease Control, Karolinska Institutet 
under approved study N42/10. SCID/beige mice were purchased from Charles River (Sulzfeld, Germany). SCID/Beige mice (8-12 weeks old) were injected subcutaneously (s.c) with J82 tumors ( $3 \times 10^{6} /$ mouse) in the right flank. When tumors were palpable $\left(>1 \mathrm{~mm}^{3}\right.$, day $10)$, mice were grouped to receive either vehicle $(n=4)$ or b-AP15 $(n=4)$ at $2.5 \mathrm{mg}$ per $\mathrm{kg}$ of body weight (i.p). The following day, mice were injected intravenously (i.v) with $2 \times 10^{6} \mathrm{NK}$ cells or $4 \times 10^{6}$ TILs. In cytotoxicity assays, in vitro killing of untreated J82 tumors was approximately 2-fold higher by NK cells compared with TILs; therefore a 1:2 ratio of infused NK cells and TILs was used. Mice were treated for a total of three cycles, receiving injections of b-AP15 on days 12, 19 and 26 and cell infusions on days 13, 20, and 27 post tumor injection.

To investigate the potential synergistic effect of combined NK and T cell therapy, immune competent male BALB/c mice were injected s.c with D2F2 cells (100,000/mouse) in the right flank. Alternatively, BALB/c mice were injected i.v with lentiviral-transduced luciferase (AMS Biotechnology, UK) D2F2 cells (100,000/mouse). Within one week, when s.c tumors were palpable $\left(>5 \mathrm{~mm}^{3}\right.$, day 6 ) or pulmonary metastases were visible by bioluminescence imaging (day 3), BALB/c mice were treated with either vehicle (PBS) or three weekly cycles of b-AP15 $(2.5 \mathrm{mg} / \mathrm{kg})$ followed by the next day infusion of NK cells $\left(0.75-1.5 \times 10^{6}\right.$ cells $)$ and/or tumor-specific T cells $\left(1-2 \times 10^{6}\right.$ cells). Mice treated with the combination of both NK and $\mathrm{T}$ cells received the same number of total cells compared to mice receiving NK or T cells alone. Tumor progression was assessed by palpation twice weekly or by in vivo bioluminescence imaging. In vivo imaging was performed by injecting mice with luciferin (3 ug/mouse, i.p). Mice were imaged the IVIS camera platform (Caliper LifeSciences Benelux \& Nordic, Belgium). The in vivo experiments were repeated twice with 4-6 mice per treatment group. 


\section{Statistical analysis}

All statistical analyses were performed using GraphPad Prism 5.0 software. The in vitro data were analyzed by paired or unpaired t-test and in vivo data were analyzed using unpaired ttest, two-way ANOVA and Log-rank (Mantel-Cox) test. Correlation tests were performed using Pearson's correlation test. p-values below 0.05 were considered statistically significant between treatment groups. 


\section{Results}

\section{Increased TRAIL-mediated killing of b-AP15 treated tumors}

b-AP15-treated J82 tumor cells were stained with Annexin V to evaluate the level of apoptosis. No change in the percentage of dead cells was observed in cells treated with $1 \mu \mathrm{M}$

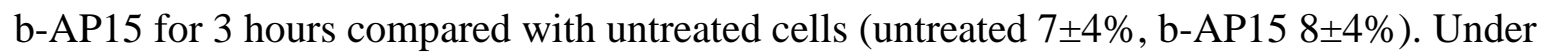
these conditions, the expression of TRAIL-R2 was significantly up-regulated $(\mathrm{p}=0.03)$ compared with untreated controls in a panel of tumor cell lines (J82, DU145, A498, HCT116, HeLa, MDA453) (Fig. 1A). In contrast, no significant change in expression of Fas was observed in these cell lines following treatment with b-AP15 (Fig. 1B). Additionally, no changes were observed in the expression of TRAIL-R1, TRAIL-R3, MHC class I, MICA/B, and Nectin-2 following treatment of J82 cells with b-AP15 (Supplementary Fig. 1C). In contrast, expression of cFLIP was down-regulated in J82 cells following exposure to b-AP15 (Supplementary Fig. 1D). When tumor cell lines were examined for susceptibility to TRAILinduced apoptosis, b-AP15 pre-treatment resulted in significantly increased TRAIL-mediated killing in several tumor cell lines including HCT116, A498, J82, RT4, MDA453, and DU145 $(\mathrm{p}=0.002)$ (Fig. 1C). Killing by recombinant FasL was higher in b-AP15 treated A498 cells compared with untreated cells. However, no increase in FasL-mediated killing was observed in any of the other cells lines after treatment with b-AP15 (p=0.07) (Fig. 1D).

\section{b-AP15 sensitizes tumor cells to TRAIL-mediated NK- and T- cell killing in vitro}

Upon activation with IL-2, human NK and T cells express TRAIL (Supplementary Fig. 2A). We next investigated whether b-AP15-treated tumor cells would be more sensitive to killing by activated NK and T cells. Indeed, human tumor cells treated with b-AP15 were 
significantly more sensitive to killing by NK ( $<<0.0002)$ and tumor (Mart1) specific T cells ( $\mathrm{p}=0.02)$ (Fig. 2A and Table 1). In contrast to our previous findings, where tumor cell lines pretreated with the proteasome inhibitor bortezomib were resistant to T cell-mediated killing [14], b-AP15 pretreated J82 and EST027 cells were highly sensitized to T cell-mediated killing relative to untreated or bortezomib treated cells (Supplementary Fig.2B). Importantly b-AP15 did not sensitize fibroblasts to NK cell-mediated killing (Table 1).

To confirm if the underlying mechanism of killing was dependent on TRAIL-R2 signaling, cytotoxicity assays were performed in the presence of neutralizing antibodies. Both NK and T cell-mediated killing of b-AP15-treated human tumors was significantly reduced in the presence of neutralizing antibodies to TRAIL. Although overall cytotoxicity was reduced in presence of the perforin inhibitor concanamycin A and neutralizing antibodies to Fas ligand, b-AP15 still sensitized tumors to NK- and T-cell-mediated killing in presence of these inhibitors (Fig. 2B). Furthermore, no significant reduction in killing were observed in presence of neutralizing antibodies to NKG2D or DNAM-1 between untreated and b-AP15 treated tumor cells (Supplementary Fig. 2C).

Given that treatment with b-AP15 results in increased TRAIL-R2 expression and decreased cFLIP expression, we next addressed which of these events are required for b-AP15-mediated sensitization to NK cell killing. An overall positive correlation in NK cell-mediated killing and expression of TRAIL-R2 was observed in tumor cell lines before and after treatment with b-AP15 ( $\mathrm{p}=0.006)$. Although an average decrease of $56 \% \pm 11 \%$ in the expression of cFLIP was observed following treatment with b-AP15 in several cell lines (J82, JOHW, JuSo, and HeLa), no significant overall correlation was found between the cFLIP expression and sensitivity to NK cell-mediated killing (Fig. 3A). Furthermore, increased NK cell-mediated killing was only observed in individual cell lines where expression of TRAIL-R2 was 
significantly increased. In contrast, NK cell-mediated killing was independent of decreased cFLIP expression after b-AP15 treatment (Fig. 3B).

\section{b-AP15 sensitizes tumor cells to adoptively infused NK and T cells in vivo.}

To investigate the therapeutic impact of b-AP15 in sensitizing tumors to human NK and T cell -mediated killing, tumor-bearing immune-deficient SCID/Beige mice were pre-treated with b-AP15 and thereafter infused with either NK or tumor-specific T cells. Treatment with bAP15, NK, or T cells alone resulted in a significantly delayed tumor progression compared with untreated mice $(\mathrm{p}<0.002$; data not shown). Furthermore, a further delay in tumor progression was observed upon infusions of NK or T cells in mice pre-treated with b-AP15 compared with mice treated with b-AP15, T, or NK cells alone ( $\mathrm{p}<0.01)$ (Fig. 4A, B, and C).

We next asked whether combined infusion of both NK and T cells would result in further delayed tumor progression in b-AP15 treated mice. In vitro, treatment with b-AP15 resulted in a minor up-regulation of TRAIL-R2 expression. Nevertheless, this increase in expression was sufficient to sensitize D2F2 tumor cells to NK and T cell -mediated killing. Furthermore, the level of murine NK cell and T cell killing of b-AP15-treated tumor cells was reduced in the presence of neutralizing antibodies to TRAIL (Supplementary Fig. 3A, B and C). In addition, RENCA, but not B16 melanoma tumor cell lines were efficiently killed by NK cells following exposure to b-AP15 compared with untreated tumor cells (Table 1). Moreover murine NK and tumor specific T cells displayed elevated IFN $\gamma$ production when co-cultured with b-AP15 treated D2F2 cells compared with those co-cultured with untreated D2F2 tumors (data not shown).

In mice bearing s.c implanted syngeneic D2F2 tumors, treatment with b-AP15, NK cells, or T cells alone did not result in reduced tumor burden compared with untreated tumor-bearing 
$\mathrm{BALB} / \mathrm{c}$ mice. After three infusions, the median tumor sizes were $334 \pm 11$ (untreated mice), $326 \pm 91$ (b-AP15 treated mice), $340 \pm 84$ (NK cell treated mice), $260 \pm 23$ ( $\mathrm{T}$ cell treated mice), and $363 \pm 25$ (NK cell $+\mathrm{T}$ cell treated mice). However, compared with mice treated with bAP15 alone or NK+T cell treated mice without b-AP-15, treatment with b-AP15 followed by infusion of both NK and T cells resulted in significantly reduced tumor burden in mice bearing s.c tumors $(\mathrm{p} \leq 0.01$; Fig. $5 \mathrm{~A})$.

In addition bioluminescence imaging of mice implanted with luciferase expressing D2F2 cells, showed a significant decrease in tumor burden in mice pre-treated with b-AP15 and coinfused with NK- and T-cells ( $\mathrm{p} \leq 0.002$, Fig. 5B and C). Similarly to the subcutaneous model, no change in tumor burden was observed after treatment with b-AP15, NK cells, T cells, or T cells and NK cells alone compared with untreated mice (data not shown). Moreover, the combined infusion of NK and T cells resulted in significantly prolonged long-term survival in mice bearing i.v tumors compared with mice receiving b-AP15 and NK cells $(p=0.001)$ or $b-$ AP15 and T cells ( $\mathrm{p}=0.001)$ (Fig. 5D). 


\section{Discussion}

Here we demonstrate that inhibition of proteasome deubiquitinating activity leads to sensitization of tumor cells to NK and T cell -mediated killing, and that the mechanism of sensitization centers upon up-regulation of TRAIL-R2. Several chemotherapeutical agents have been shown to increase TRAIL receptor expression on tumor cells $[17,18]$. We and others previously demonstrated that treatment with the proteasome inhibitor bortezomib increases TRAIL-R2 expression on tumor cells resulting in an increased killing by activated NK cells via TRAIL in vitro [12,19]. Whether bortezomib can sensitize tumor cells to T cellmediated killing is less clear. Bortezomib was recently shown to inhibit NF- $\mathrm{BB}$ activity and restore MART-1 expression and pro-apoptotic signaling, resulting in sensitization of melanoma tumors to killing by TCR-engineered CTLs [20]. We have demonstrated that bortezomib-treated tumor cells are resistant to killing by tumor-specific TILs due to impaired antigen processing and presentation [14]. Differences in T cell preparation and source may account for these differences. In accordance with our previous findings, we show that treatment with bortezomib results in increased NK but abrogated T cell-mediated killing of tumor cells. However, the same tumor cells were rendered sensitive to killing by both NK and T cells following exposure to the proteasome deubiquitinatinase inhibitor b-AP15. b-AP15 inhibits the deubiquitinating activity of the regulatory 19S particle of the proteasome resulting in impaired degradation of cellular proteasome substrates [16]. However, unlike bortezomib the proteolytic activities of the 20S core proteasome is not inhibited, thus immunoproteasome processing and presentation of antigenic peptides to $\mathrm{T}$ cells is not expected to be impaired [16]. Therefore, we hypothesized that b-AP15 may enhance NK cell killing in a manner similar to bortezomib, but without dampening antigen processing and $\mathrm{T}$ cell-mediated killing. 
Overall, b-AP15 induced up-regulation of TRAIL-R2 and down-regulation of cFLIP in human tumor cell lines in vitro. We found that up-regulation of TRAIL-R2, rather than downregulation of cFLIP, was associated with b-AP15-induced sensitization to NK cell-mediated killing. We previously demonstrated that the amplitude of NK cell-mediated lysis positively correlated with the degree of induction of TRAIL-R2 expression following treatment with bortezomib [19]. Several studies have demonstrated that down-regulation of cFLIP in tumor cells is required for sensitization to TRAIL-mediated killing [21,22]. In contrast, Ganten et al. showed that proteasome inhibition with MG132 sensitized hepatocellular carcinoma cells despite high levels of cFLIP [23].

Although NK and T cell -mediated killing of b-AP15 treated tumor cells was reduced in presence of neutralizing antibodies to TRAIL, killing was also reduced in the presence of neutralizing antibodies to Fas ligand or CMA. Therefore, we cannot exclude that b-AP15 sensitizes tumor cells partly to Fas ligand and perforin-mediated killing. This interpretation would be consistent with the report by Hallett et al. that treatment with proteasome inhibitors can sensitize tumor cells not only to TRAIL-mediated killing, but also to killing via Fas ligand in vitro [24].

We have previously demonstrated that treatment with b-A15 results in reduced metastases and tumor growth [16]. Similarly, in this study we observed delayed tumor progression (J82 bladder cancer) in immune deficient SCID/Beige mice upon weekly treatment with b-AP15 compared to untreated mice. Infusion of either NK or T cells significantly delayed tumor progression in tumor-bearing SCID/Beige mice following pre-treatment with b-AP15 relative to mice receiving b-AP15 only. However, we did not observe any delay in tumor progression in immune competent $\mathrm{BALB} / \mathrm{c}$ mice after infusion of $\mathrm{NK}$ or $\mathrm{T}$ cells or after treatment with bAP15. The discrepancy in results between SCID/Beige and BALB/c mice may be due to the rapid growth rate of the syngeneic D2F2 tumors (day 21; 359 $\pm 27 \mathrm{~mm}^{3}$ ) compared with the 
J82 tumor xenografts (day 20; $12.5 \pm 1.5 \mathrm{~mm}^{3}$ ). In addition, D2F2 tumors could be less sensitive to treatment due to the infusion of fewer lymphocytes (BALB/c; $0.75-2 \times 10^{6}$, SCID/Beige; $2-4 \times 10^{6}$ ) in this model.

Given that tumor cells within a tumor mass have a variable expression of MHC class I [6], combined adoptive cell therapy with NK and tumor-specific T cells may result in better clinical responses compared with infusion of NK or T cells alone. However, several studies have demonstrated that NK and T cells may counteract each other. NK cells play an important role in maintaining immune homeostasis by regulating expansion of activated $\mathrm{T}$ cells through p21-mediated cell cycle arrest [25]. Olson et al. demonstrated that NK cells can inhibit and kill autologous alloreactive T cells [26]. Furthermore, activated T cells can inhibit NK cellmediated tumor rejection in mice [27]. To investigate whether combined infusion of NK and T cells would result in synergistic anti-tumor effects, tumor-bearing BALB/c mice were treated with b-AP15 followed by infusion of syngeneic NK and/or T cells. Following b-AP15 treatment, infusion of both NK and T cells showed a significantly reduced tumor burden compared with mice treated with either NK or T cells. The reduced tumor burden in b-AP15 treated mice receiving a combined infusion of $\mathrm{NK}$ and $\mathrm{T}$ cells resulted in a significantly extended survival.

Several clinical studies have evaluated TRAIL receptor targeting in solid tumors. These studies concluded that TRAIL targeting needs to be combined with chemotherapy to generate objective clinical response rates [28-30]. Combined therapy with drugs like b-AP15 and adoptive cell therapy may have additional benefits over the use of combining immunosensitizing drugs and agonistic monoclonal antibodies against TRAIL or recombinant TRAIL for several reasons. The half-life of anti-TRAIL receptor antibodies and recombinant TRAIL is approximately 17 days and less than one hour respectively [31]. Adoptively transferred $\mathrm{T}$ and NK cells can be detected several months after infusion potentially resulting 
in sustained anti-tumor effects $[3,32]$. Our results indicate that following exposure to b-AP15, tumor cells remained sensitive to NK cell killing for 72 hours in vitro, thus providing a relatively long therapeutic window for NK cell therapy (data not shown). Infused lymphocytes upon tumor interaction, produce pro-inflammatory cytokines that contribute to tumor eradication. Such cytokines may also recruit other inflammatory cells to the tumor microenvironment further heightening the anti-tumor immune response. In addition, tumor cells can develop resistance to TRAIL targeting by monoclonal antibodies. Since NK and T cells use a variety of cytolytic mechanism to induce cell death, drug-induced sensitization combined with adoptive cell infusion may offer a broader anti-tumor effect.

Our findings demonstrate that inhibition of proteasome deubiquitinating activity with b-AP15 renders tumor cells sensitive to killing by NK and T cells. Since combined therapy with NK and $\mathrm{T}$ cells increase the chances of targeting tumor cells with variable MHC class I expression, b-AP15 pre-treatment followed by infusion of NK and T cells may represent a valuable therapeutic option for the treatment of a wide variety of cancers. 


\section{Acknowledgments}

We thank Dr. Rolf Kiessling and Helena Tufvesson Stiller, for intellectual support, and Juan

Castro for assistance with flow cytometry and STR analysis, at the Department of OncologyPathology, Stockholm, Sweden. We also thank Dr. Nick Tobin for revising the manuscript. We would also like to thank staff at the animal facility at the Department of Microbiology, Tumor and Cell Biology and The Swedish Institute for Communicable Disease Control, Karolinska Institutet.

\section{Conflict of interest}

None of the authors have any conflict of interest to declare. The content of this work has not been published in the form of a meeting abstract or in any journal.

\section{Grant Support}

This work was supported by funding from The Swedish Research Council, The Swedish Cancer Society, The European Research Council, Karolinska Institutet, Jeanssons Stiftelser, Åke Wibergs Stiftelse, Magnus Bergvalls Stiftelse, Fredrik och Ingrid Thurings Stiftelse, Stiftelsen Clas Groschinskys Minnesfond, and The Swedish Society of Medicine 


\section{Figure legends}

Fig. 1: Sub-apoptotic doses of b-AP15 increase TRAIL-R2 and sensitizes human tumor cells to TRAIL-mediated killing in vitro

TRAIL-R2 (A) and Fas (B) expression in untreated and b-AP15 treated [1 uM, 3 hours] J82

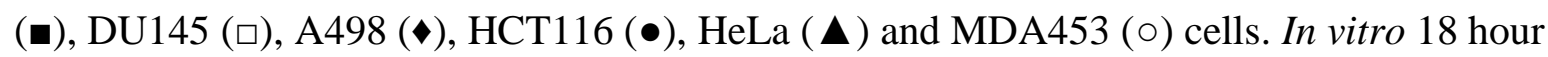
51Cr-release assay of recombinant TRAIL (C) [100 ng/ml] or recombinant FasL (D) [150

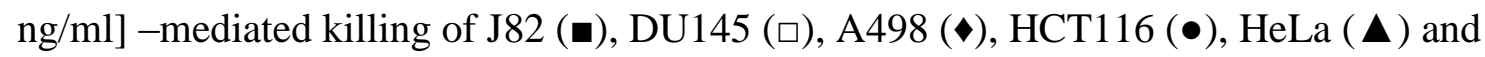
MDA453 (o) tumor cells ( $n=2)$. Statistical analysis of mean fluorescence intensity (MFI) of TRAIL-R2 expression $(n=2)$; was performed by student's paired T-test (mean+SEM). $n=$ numbers of replicates.

Fig. 2: b-AP15 sensitizes human tumor cell lines to NK and T cell -mediated killing via TRAIL.

A) Human tumor cell lines J82, MDA453, HCT116, EST152, and EST027 were treated with $1 \mathrm{uM} \mathrm{b}$-AP15 for 3 hours and tested for susceptibility to killing by human NK cells and T

cells in an 18 hour 51Cr-release assay (n=3). B) J82 cells were treated with b-AP15 [1 uM, 3 hours] and tested for killing by NK or T cells in presence of neutralizing antibodies to TRAIL or FasL or in presence of Concanamycin A (CMA) ( $n=3$, mean \pm SEM). The statistical significance was calculated by student's paired T-test (mean+SEM). ${ }^{*} \mathrm{p}<0.05$.

Fig. 3: Increased TRAIL-R2 but not decreased cFLIP expression is associated with bAP15-induced sensitization to NK cell-mediated killing.

A) The Pearson's correlation test between NK cell-mediated killing and expression of TRAIL-R2 or cFLIP expression was performed in tumor cell lines including J82, JOHW, DU145, JuSo, HeLa, A498, HCT116, MCF7, and MDA453 before and after treatment with b- 
AP15 (n=2). B) J82, JOHW and HCT116 were treated with b-AP15 or left untreated and tested for susceptibility to killing by human NK cells in an 18 hour 51 Cr-release assay $(n=3$; mean \pm SEM), analyzed for TRAIL-R2 $(n=2)$ and cFLIP expression $(n=2)$ by flow cytometry and Western Blot respectively.

Fig. 4: Adoptive infusion of human NK or T cells following b-AP15 treatment delay tumor progression in immune-deficient mice

SCID/Beige mice were injected (s.c) with $3 \times 10^{6}$ J82 cells and treated with b-AP15 [2.5 $\mathrm{mg} / \mathrm{kg}$ ] on days 12, 19, and 26 (A) followed by infusion of either NK cells (B) or Mart-1 specific T cells (C) on days 13, 20, and 27 post tumor injection. Tumor size was measured by palpation twice every week. The statistical significance was calculated by two-way ANOVA and p-values obtained from the interaction test between all groups compared to groups treated with b-AP15 and NK cells or b-AP15 and T cells.

Fig. 5: NK- and T- cell combined therapy delay tumor progression and prolong survival in b-AP15 pre-treated BALB/c mice

BALB/c mice were injected s.c $(A)(n=4)$ or i.v (B and C) $(n=5)$ with $0.1 \times 10^{6}$ D2F2 cells and treated with b-AP15 on days 7, 14, and 21 or 3,10 and 17 respectively or left untreated followed by the next day infusion of NK cells, T cells, or NK and T cells. (A) Tumor size on day 22, (B) Bioluminescence imaging on day 27 after tumor inoculation or (C)

Bioluminescent images of two representative mice of (B). (D) Survival of tumor-bearing (i.v tumors) mice. The statistical significance of A) and B) was calculated by two-way ANOVA and p-values obtained from single row test between all groups and group receiving NK cells + T cells + b-AP15. Statistical analysis for survival was calculated by Log-rank (Mantel-Cox) test $(n=6) . n$ indicate number of mice in each treatment group. 
Table 1. NK and T cell -mediated killing of tumor cell lines after treatment with $b$ AP15.

Human and mouse tumor cell lines of different origin were treated with b-AP15 [1 uM, 3 hours] and tested for susceptibility to killing by NK or T cells in an 18 hour 51Cr-release assay at E:T ratio ranging between $0.3-3: 1$ or 3-9:1 respectively. p-values are calculated by student's paired T-test based on fold-change values. Experiments were repeated at least twice for every cell line. 


\section{References}

1. Rosenberg SA, Yang JC, Sherry RM, Kammula US, Hughes MS, Phan GQ, Citrin DE, Restifo NP, Robbins PF, Wunderlich JR, Morton KE, Laurencot CM, Steinberg SM, White DE, Dudley ME (2011) Durable complete responses in heavily pretreated patients with metastatic melanoma using T-cell transfer immunotherapy. Clin Cancer Res 17 (13):4550-4557.

2. June CH (2007) Adoptive T cell therapy for cancer in the clinic. J Clin Invest 117 (6):1466-1476. 3. Parkhurst MR, Riley JP, Dudley ME, Rosenberg SA (2011) Adoptive transfer of autologous natural killer cells leads to high levels of circulating natural killer cells but does not mediate tumor regression. Clin Cancer Res 17 (19):6287-6297.

4. Bubenik J (2003) Tumour MHC class I downregulation and immunotherapy (Review). Oncol Rep 10 (6):2005-2008.

5. Marincola FM, Jaffee EM, Hicklin DJ, Ferrone S (2000) Escape of human solid tumors from T-cell recognition: molecular mechanisms and functional significance. Adv Immunol 74:181-273.

6. Al-Batran SE, Rafiyan MR, Atmaca A, Neumann A, Karbach J, Bender A, Weidmann E, Altmannsberger HM, Knuth A, Jager E (2005) Intratumoral T-cell infiltrates and MHC class I expression in patients with stage IV melanoma. Cancer Res 65 (9):3937-3941.

7. Milstein O, Hagin D, Lask A, Reich-Zeliger S, Shezen E, Ophir E, Eidelstein Y, Afik R, Antebi YE, Dustin ML, Reisner Y (2011) CTLs respond with activation and granule secretion when serving as targets for T-cell recognition. Blood 117 (3):1042-1052.

8. Arancia G, Malorni W, Donelli G (1990) Cellular mechanisms of lymphocyte-mediated lysis of tumor cells. Ann Ist Super Sanita 26 (3-4):369-384.

9. Jenne DE, Tschopp J (1988) Granzymes, a family of serine proteases released from granules of cytolytic T lymphocytes upon T cell receptor stimulation. Immunol Rev 103:53-71.

10. Berke G (1994) The binding and lysis of target cells by cytotoxic lymphocytes: molecular and cellular aspects. Annu Rev Immunol 12:735-773.

11. Yong AS, Keyvanfar K, Hensel N, Eniafe R, Savani BN, Berg M, Lundqvist A, Adams S, Sloand EM, Goldman JM, Childs R, Barrett AJ (2009) Primitive quiescent CD34+ cells in chronic myeloid leukemia are targeted by in vitro expanded natural killer cells, which are functionally enhanced by bortezomib. Blood 113 (4):875-882.

12. Liu X, Yue P, Chen S, Hu L, Lonial S, Khuri FR, Sun SY (2007) The proteasome inhibitor PS-341 (bortezomib) up-regulates DR5 expression leading to induction of apoptosis and enhancement of TRAIL-induced apoptosis despite up-regulation of c-FLIP and survivin expression in human NSCLC cells. Cancer Res 67 (10):4981-4988.

13. Shanker A, Brooks AD, Tristan CA, Wine JW, Elliott PJ, Yagita H, Takeda K, Smyth MJ, Murphy WJ, Sayers TJ (2008) Treating metastatic solid tumors with bortezomib and a tumor necrosis factorrelated apoptosis-inducing ligand receptor agonist antibody. J Natl Cancer Inst 100 (9):649-662. 14. Lundqvist A, Su S, Rao S, Childs R (2010) Cutting edge: bortezomib-treated tumors sensitized to NK cell apoptosis paradoxically acquire resistance to antigen-specific T cells. J Immunol 184 (3):11391142.

15. Baumann P, Muller K, Mandl-Weber S, Leban J, Doblhofer R, Ammendola A, Baumgartner R, Oduncu F, Schmidmaier R (2009) The peptide-semicarbazone S-2209, a representative of a new class of proteasome inhibitors, induces apoptosis and cell growth arrest in multiple myeloma cells. $\mathrm{Br} \mathrm{J}$ Haematol 144 (6):875-886.

16. D'Arcy P, Brnjic S, Olofsson MH, Fryknas M, Lindsten K, De Cesare M, Perego P, Sadeghi B, Hassan $M$, Larsson R, Linder $S$ (2011) Inhibition of proteasome deubiquitinating activity as a new cancer therapy. Nat Med 17 (12):1636-1640.

17. Kang YJ, Kim IY, Kim EH, Yoon MJ, Kim SU, Kwon TK, Choi KS (2011) Paxilline enhances TRAILmediated apoptosis of glioma cells via modulation of c-FLIP, survivin and DR5. Exp Mol Med 43

(1):24-34. 
18. Moon MH, Jeong JK, Seo JS, Seol JW, Lee YJ, Xue M, Jackson CJ, Park SY (2011) Bisphosphonate enhances TRAIL sensitivity to human osteosarcoma cells via death receptor 5 upregulation. Exp Mol Med 43 (3):138-145.

19. Lundqvist A, Abrams SI, Schrump DS, Alvarez G, Suffredini D, Berg M, Childs R (2006) Bortezomib and depsipeptide sensitize tumors to tumor necrosis factor-related apoptosis-inducing ligand: a novel method to potentiate natural killer cell tumor cytotoxicity. Cancer Res 66 (14):7317-7325.

20. Jazirehi AR, Economou JS (2012) Proteasome inhibition blocks NF-kappaB and ERK1/2 pathways, restores antigen expression, and sensitizes resistant human melanoma to TCR-engineered CTLs. Mol Cancer Ther 11 (6):1332-1341.

21. Zhao X, Qiu W, Kung J, Peng X, Yegappan M, Yen-Lieberman B, Hsi ED (2008) Bortezomib induces caspase-dependent apoptosis in Hodgkin lymphoma cell lines and is associated with reduced c-FLIP expression: a gene expression profiling study with implications for potential combination therapies. Leuk Res 32 (2):275-285.

22. White SJ, Lu P, Keller GM, Voelkel-Johnson C (2006) Targeting the short form of cFLIP by RNA interference is sufficient to enhance TRAIL sensitivity in PC3 prostate carcinoma cells. Cancer Biol Ther 5 (12):1618-1623.

23. Ganten TM, Koschny R, Haas TL, Sykora J, Li-Weber M, Herzer K, Walczak H (2005) Proteasome inhibition sensitizes hepatocellular carcinoma cells, but not human hepatocytes, to TRAIL. Hepatology 42 (3):588-597.

24. Hallett WH, Ames E, Motarjemi M, Barao I, Shanker A, Tamang DL, Sayers TJ, Hudig D, Murphy WJ (2008) Sensitization of tumor cells to NK cell-mediated killing by proteasome inhibition. J Immunol 180 (1):163-170.

25. Trivedi PP, Roberts PC, Wolf NA, Swanborg RH (2005) NK cells inhibit T cell proliferation via p21mediated cell cycle arrest. J Immunol 174 (8):4590-4597.

26. Olson JA, Leveson-Gower DB, Gill S, Baker J, Beilhack A, Negrin RS (2010) NK cells mediate reduction of GVHD by inhibiting activated, alloreactive T cells while retaining GVT effects. Blood 115 (21):4293-4301.

27. Wang XJ, Hu J, Yuan J, Peng YM, Gui L, He WF, Tan J, Luo GX, Wu J (2009) Activated T cells inhibit NK cell-mediated tumour rejection. Scand J Immunol 69 (4):337-341.

28. Soria JC, Smit E, Khayat D, Besse B, Yang X, Hsu CP, Reese D, Wiezorek J, Blackhall F (2010) Phase $1 \mathrm{~b}$ study of dulanermin (recombinant human Apo2L/TRAIL) in combination with paclitaxel, carboplatin, and bevacizumab in patients with advanced non-squamous non-small-cell lung cancer. J Clin Oncol 28 (9):1527-1533.

29. Mom CH, Verweij J, Oldenhuis CN, Gietema JA, Fox NL, Miceli R, Eskens FA, Loos WJ, de Vries EG, Sleijfer S (2009) Mapatumumab, a fully human agonistic monoclonal antibody that targets TRAIL-R1, in combination with gemcitabine and cisplatin: a phase I study. Clin Cancer Res 15 (17):5584-5590.

30. Leong S, Cohen RB, Gustafson DL, Langer CJ, Camidge DR, Padavic K, Gore L, Smith M, Chow LQ, von Mehren M, O'Bryant C, Hariharan S, Diab S, Fox NL, Miceli R, Eckhardt SG (2009) Mapatumumab, an antibody targeting TRAIL-R1, in combination with paclitaxel and carboplatin in patients with advanced solid malignancies: results of a phase I and pharmacokinetic study. J Clin Oncol 27 (26):4413-4421.

31. Duiker EW, Mom CH, de Jong S, Willemse PH, Gietema JA, van der Zee AG, de Vries EG (2006) The clinical trail of TRAIL. Eur J Cancer 42 (14):2233-2240.

32. Huang J, Khong HT, Dudley ME, El-Gamil M, Li YF, Rosenberg SA, Robbins PF (2005) Survival, persistence, and progressive differentiation of adoptively transferred tumor-reactive $T$ cells associated with tumor regression. J Immunother 28 (3):258-267. 


\begin{tabular}{|c|c|c|c|c|c|c|c|}
\hline & & Cell line & Cell type & Untr. & b-AP15 & $\begin{array}{l}\text { fold } \\
\text { change }\end{array}$ & $\begin{array}{l}\mathrm{E}: \mathrm{T} \\
\text { ratio }\end{array}$ \\
\hline \multirow{28}{*}{ 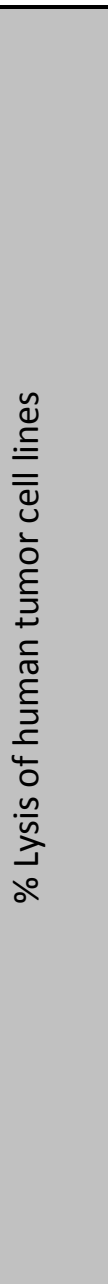 } & \multirow{21}{*}{$\begin{array}{l}\cong \\
\overline{\bar{U}} \\
\underline{z}\end{array}$} & EST152 & Skin & 18.6 & 32.6 & 1.7 & $1: 1$ \\
\hline & & EST027 & Skin & 24.0 & 37.3 & 1.5 & $1: 1$ \\
\hline & & EST049 & Skin & 26.5 & 33.0 & 1.2 & $1: 1$ \\
\hline & & EST115* & Skin & 32.0 & 39.0 & 1.2 & $2.5: 1$ \\
\hline & & EST025 & Skin & 22.7 & 46.3 & 2.0 & $2.5: 1$ \\
\hline & & JuSo & Skin & 5.0 & 7.0 & 1.4 & $1: 1$ \\
\hline & & MDA453 & Breast & 8.0 & 17.3 & 2.2 & $1: 1$ \\
\hline & & MCF-7 & Breast & 31.0 & 31.0 & 1.0 & $3: 1$ \\
\hline & & MDA484 & Breast & 9.0 & 29.0 & 3.2 & $1: 1$ \\
\hline & & PC3 & Prostate & 12.0 & 22.0 & 1.8 & $1.25: 1$ \\
\hline & & DU145 & Prostate & 9.0 & 22.0 & 2.4 & $0.3: 1$ \\
\hline & & J82 & Bladder & 13.6 & 36.0 & 2.6 & $1: 1$ \\
\hline & & RT4 & Bladder & 29.0 & 38.0 & 1.3 & $1.25: 1$ \\
\hline & & $\mathrm{JOHW}$ & Bladder & 12.0 & 12.0 & 1.0 & $2: 1$ \\
\hline & & A498 & Kidney & 13.0 & 24.0 & 2.4 & $1: 1$ \\
\hline & & HCT116 & Colon & 10.3 & 26.6 & 2.6 & $1: 1$ \\
\hline & & HEP-G & Liver & 16.0 & 32.0 & 2.0 & $1: 1$ \\
\hline & & SKOV3 & Ovarian & 2.0 & 23.0 & 11.5 & $3: 1$ \\
\hline & & HeLa & Ovarian & 24.0 & 89.0 & 3.7 & $3: 1$ \\
\hline & & BJ1 & Fibroblast & 5.0 & 5.0 & 1.0 & $3: 1$ \\
\hline & & p-value & & & $=0.0002$ & & \\
\hline & \multirow{7}{*}{$\begin{array}{l}\stackrel{\circlearrowleft}{\overline{\mathcal{U}}} \\
\vdash\end{array}$} & EST152 & Skin & 12.0 & 35.0 & 2.1 & $5: 1$ \\
\hline & & EST027 & Skin & 15.0 & 39.0 & 2.8 & $3: 1$ \\
\hline & & EST049 & Skin & 14.0 & 16.0 & 0.0 & $5: 1$ \\
\hline & & EST115* & Skin & 6.1 & 6.1 & 1.1 & $5: 1$ \\
\hline & & EST025 & Skin & 17.7 & 32.7 & 1.9 & $9: 1$ \\
\hline & & J82 & Bladder & 4.0 & 23.0 & 5.75 & $5: 1$ \\
\hline & & $p$-value & & & $=0.02$ & & \\
\hline \multirow{5}{*}{ 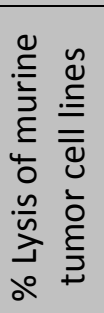 } & \multirow{3}{*}{$\begin{array}{l}\cong \\
\overline{\bar{U}} \\
\underline{z}\end{array}$} & D2F2 & Breast & 14.0 & 32.0 & 2.3 & $2.5: 1$ \\
\hline & & B16 & Melanoma & 11.0 & 11.0 & 1.0 & $2.5: 1$ \\
\hline & & RENCA & Kidney & 15.0 & 46.0 & 3.0 & $5: 1$ \\
\hline & \multirow[b]{2}{*}{$\begin{array}{l}\cong \\
\bar{\Xi} \\
\vdash\end{array}$} & D2F2 & Breast & 18.0 & 37.0 & 2.1 & $7.5: 1$ \\
\hline & & RENCA & Kidney & 6.0 & 6.0 & 1.0 & $5: 1$ \\
\hline
\end{tabular}

*The cell line is not HLA-matched 
A)

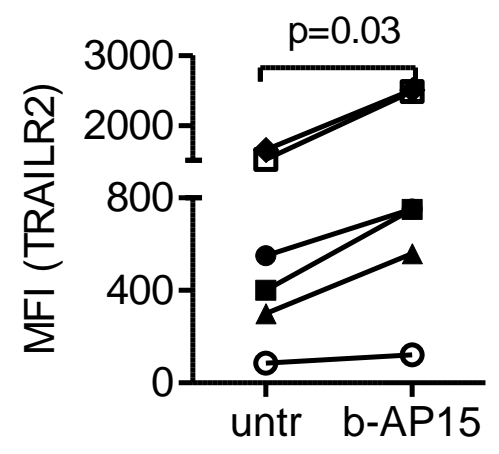

C) Recombinant TRAIL

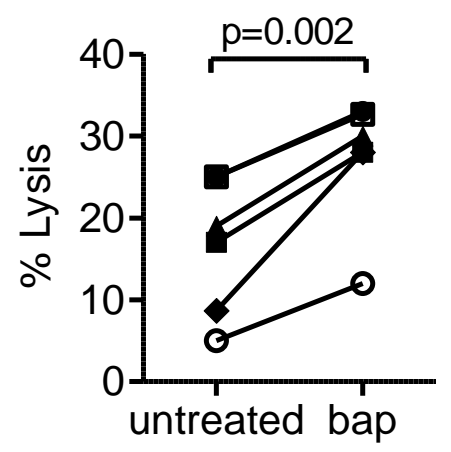

B)

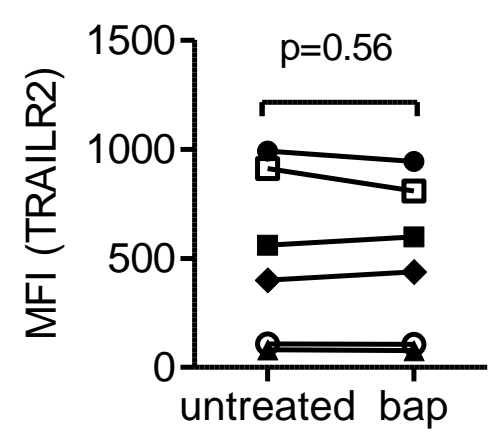

D) Recombinant FasL

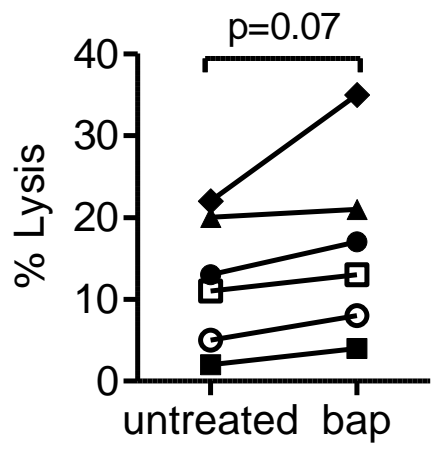


Figure 2.

A)

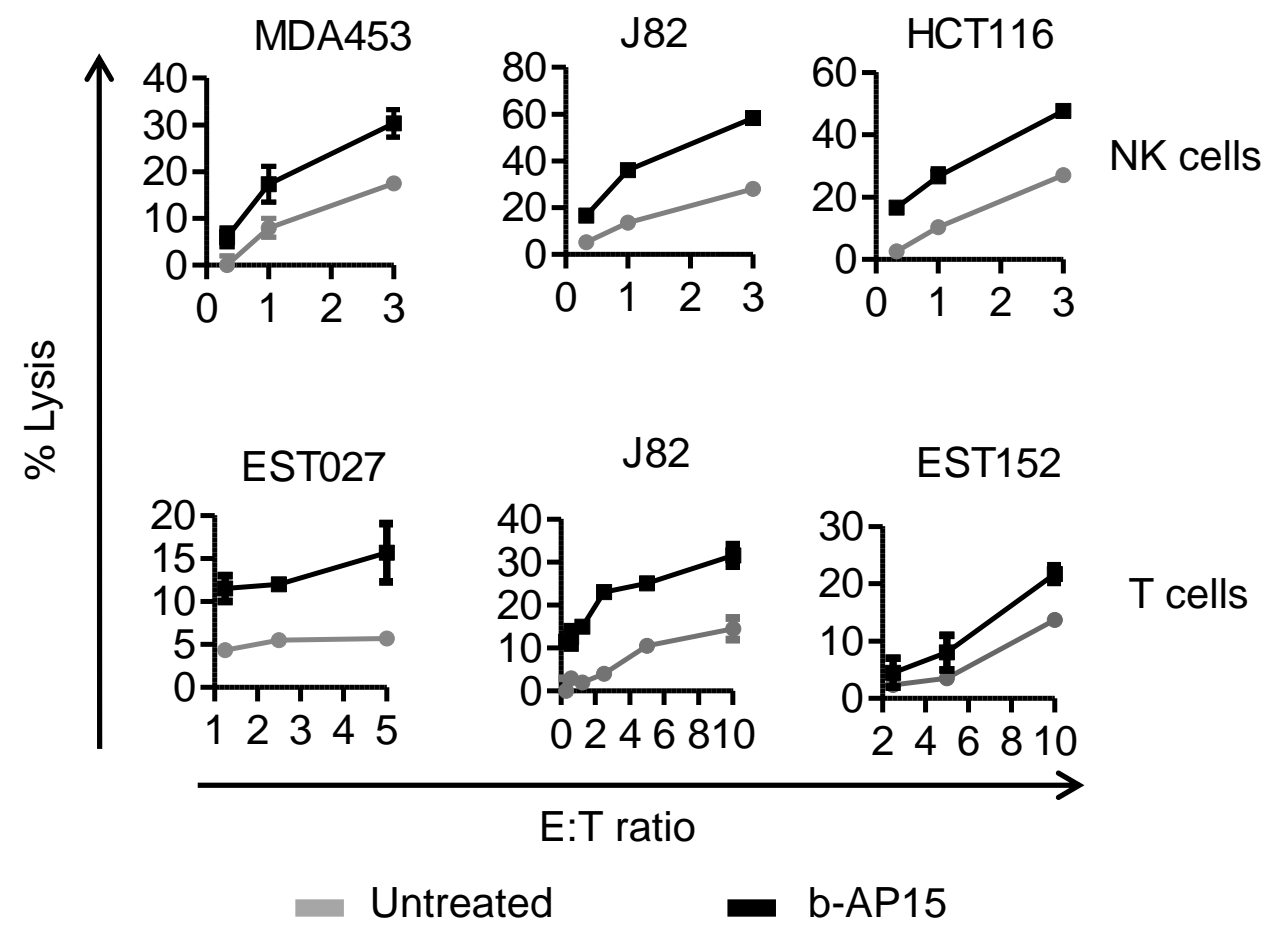

B)

NK cell

T cell
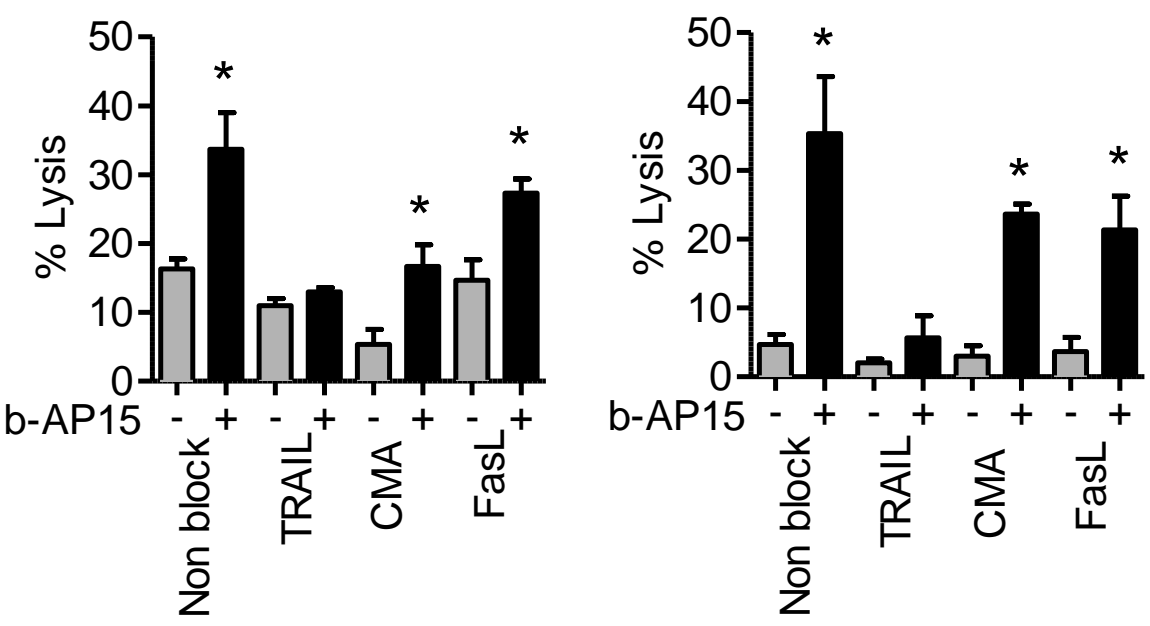
Figure 3.

A)
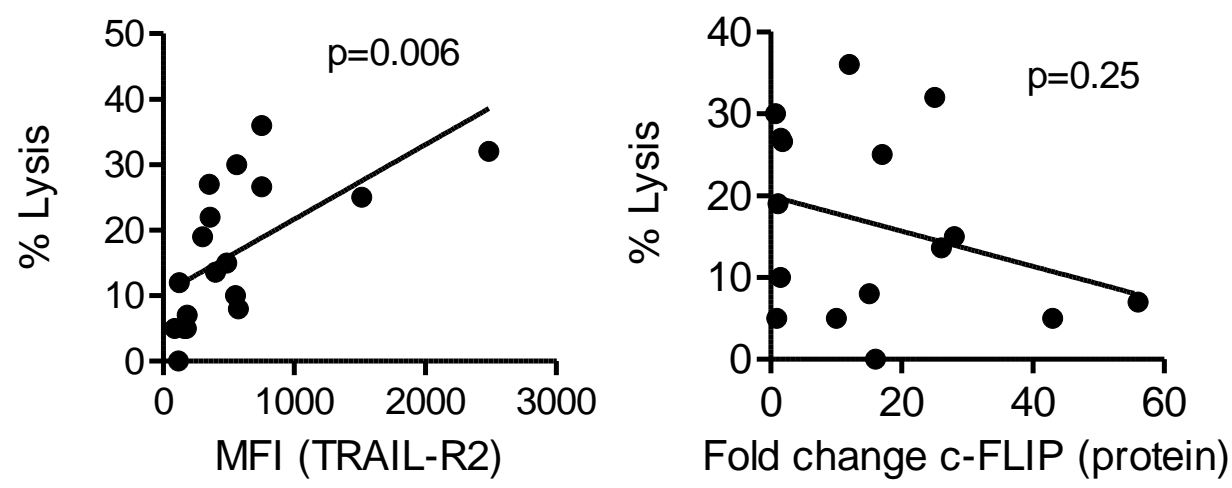

B)
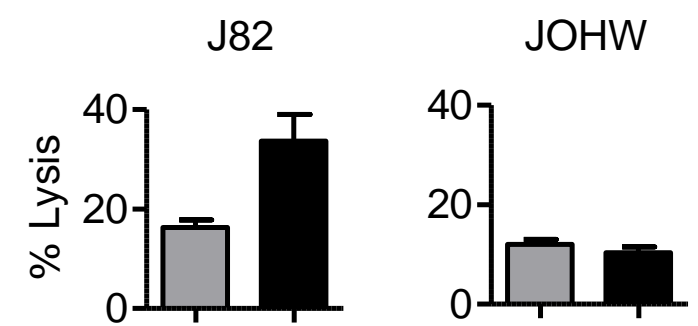

HCT116
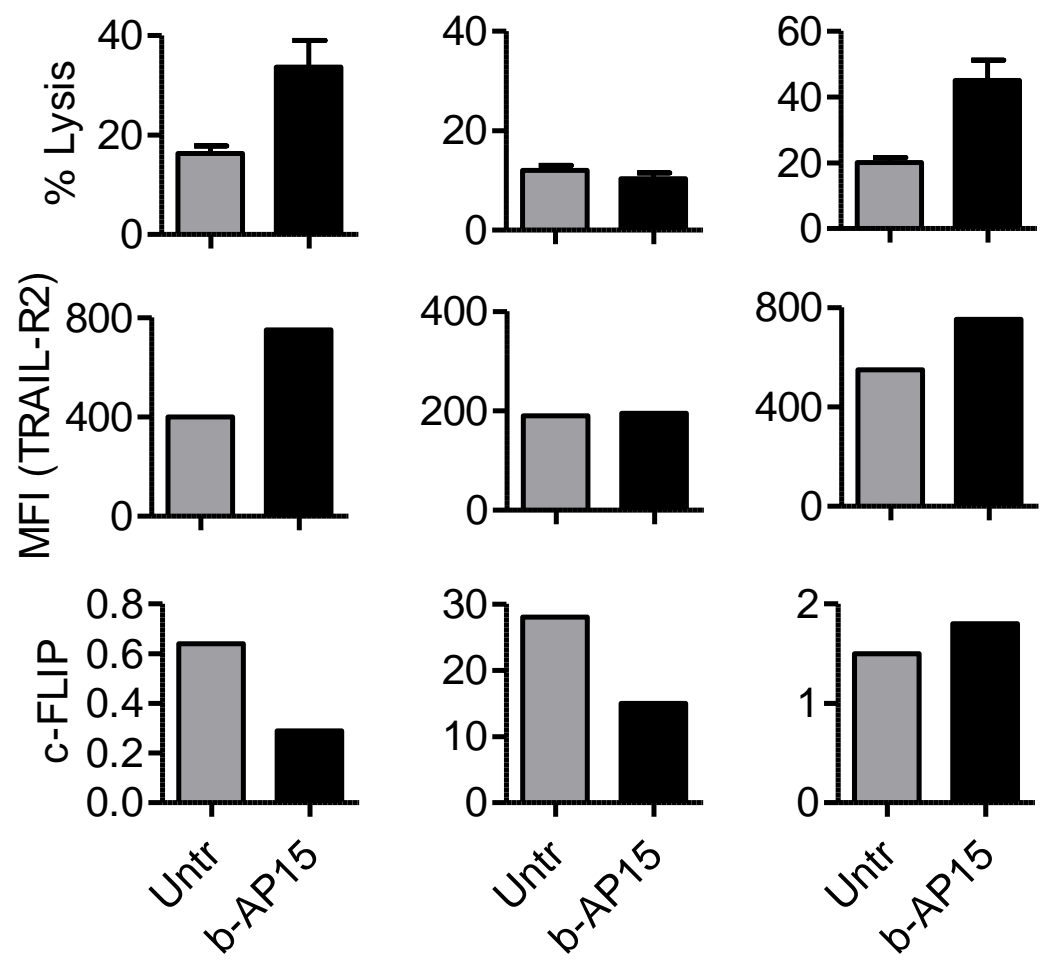


\section{Figure 4.}

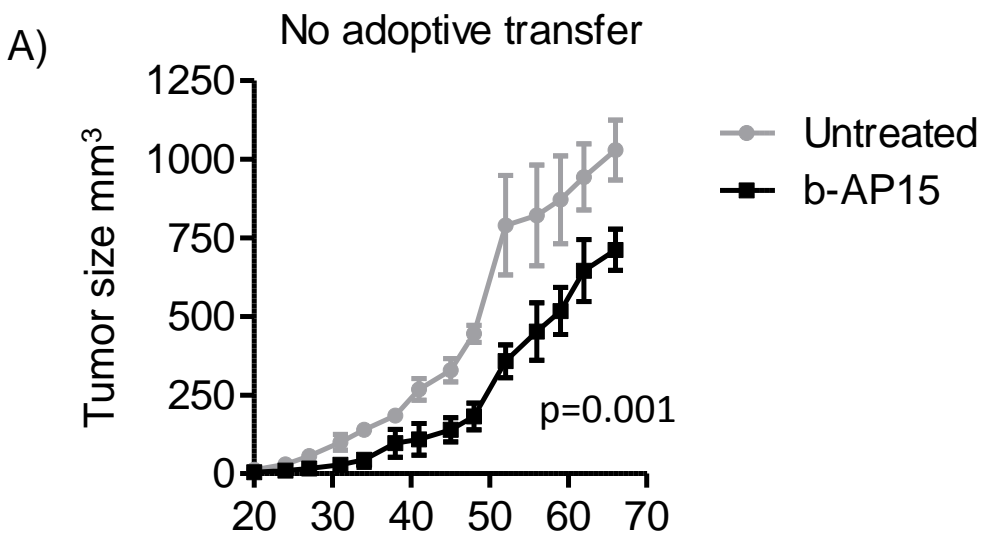

Days post tumor injection

B)

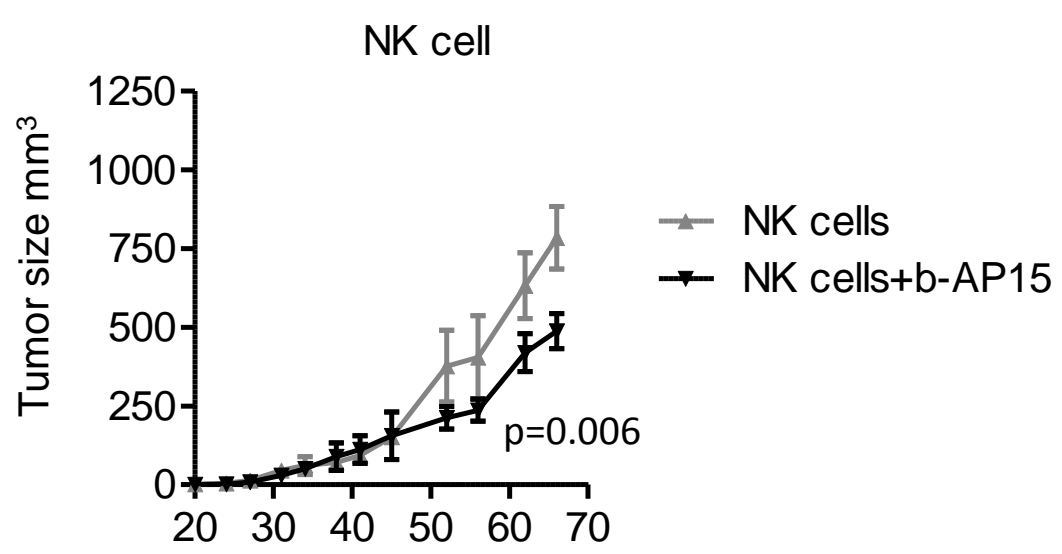

Days post tumor injection

C)

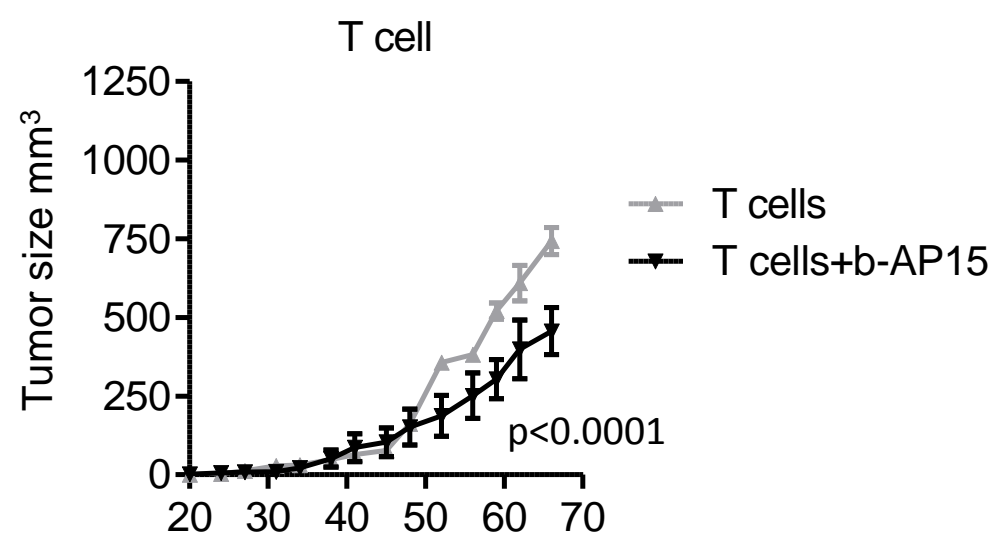

Days post tumor injection 
Figure 5.

A)

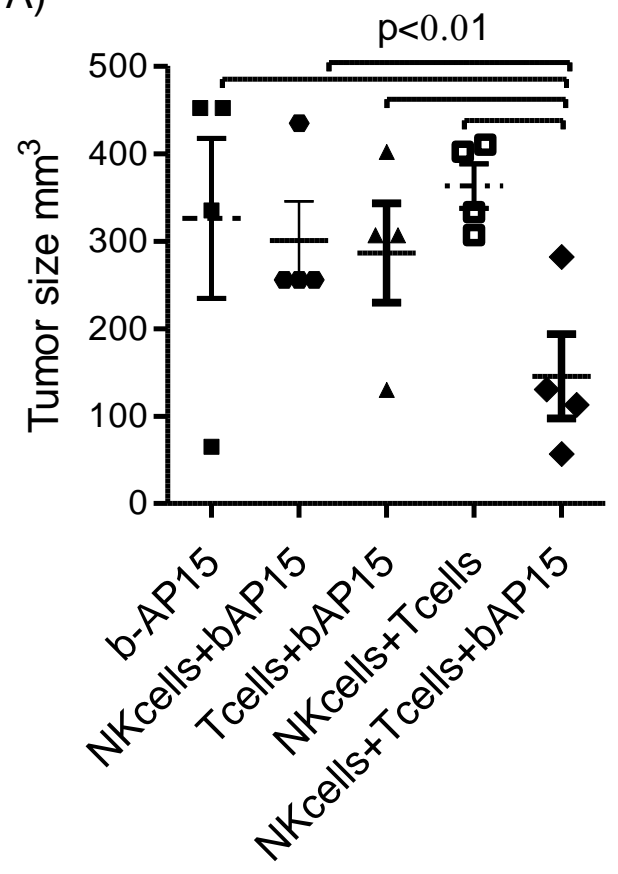

B)

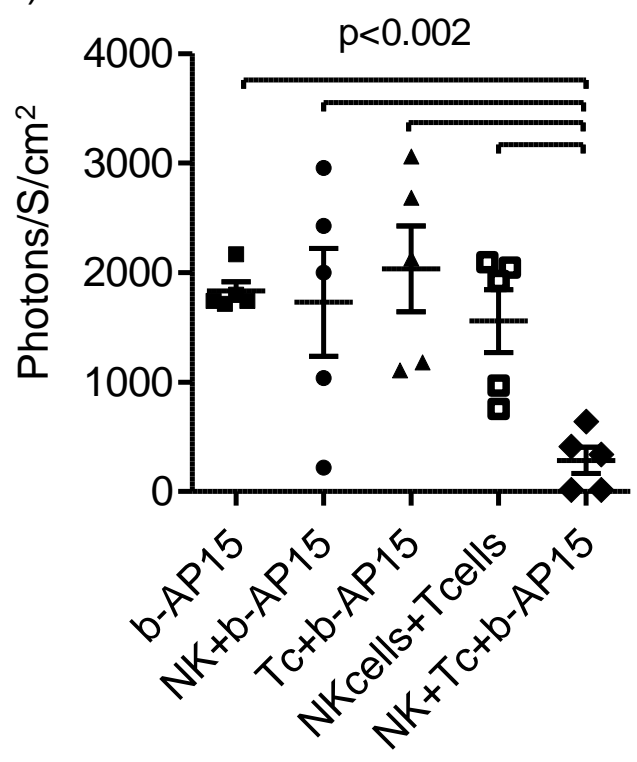

C)

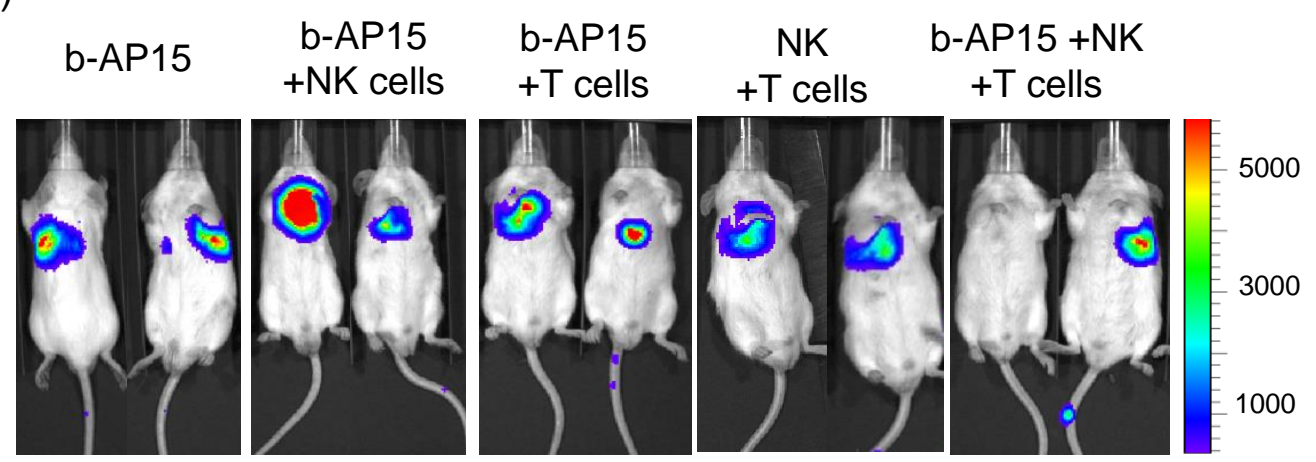

D)

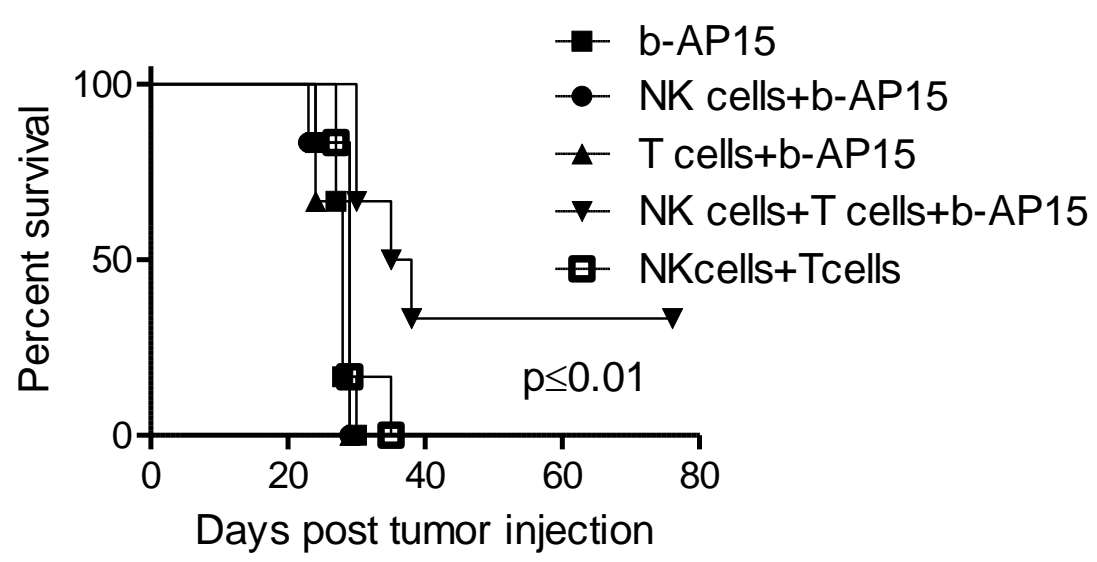


Cancer Immunology, Immunotherapy (submitted in 2013) - Dhifaf Sarhan et al.

A)

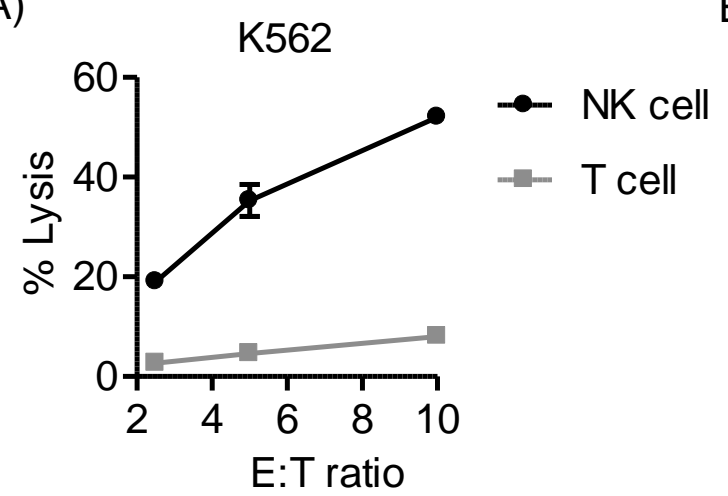

B)

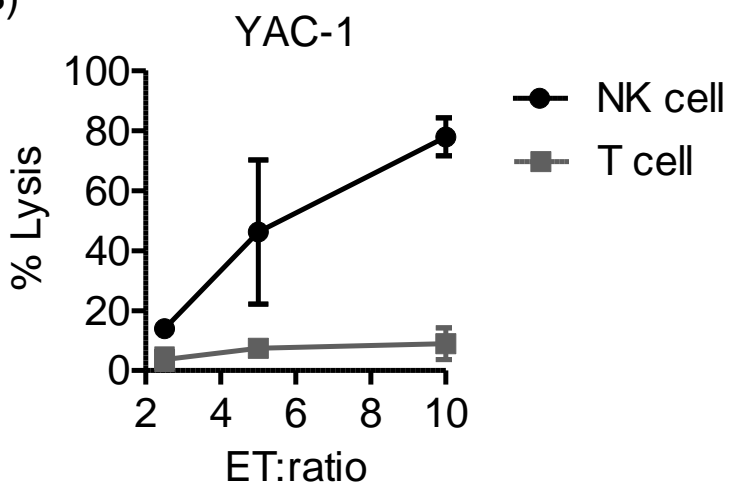

C)

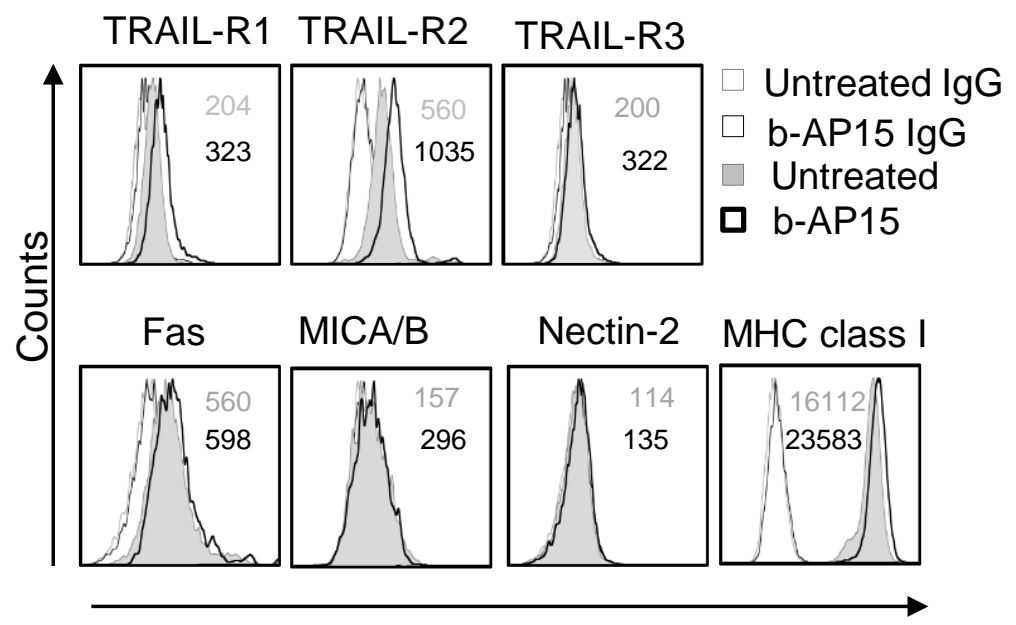

Fluorescence Intensity

D)

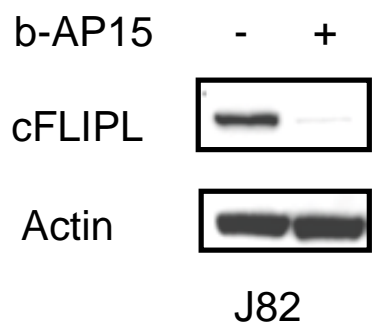

Human and murine NK and T cell -mediated cytotoxicity of A) K562 or B) YAC-1 cells respectively. (C) Flow cytometry analysis of TRAIL-R1, -R2, -R3, Fas, MICA/B, Nectin-2 and MHC class I expression in untreated and b-AP15 treated [1 uM, 3 hours] J82 cells. D) cFLIP expression of J82 cells was analyzed by Western Blot before and after b-AP15 treatment. 
Cancer Immunology, Immunotherapy (submitted in 2013) - Dhifaf Sarhan et al.

A)

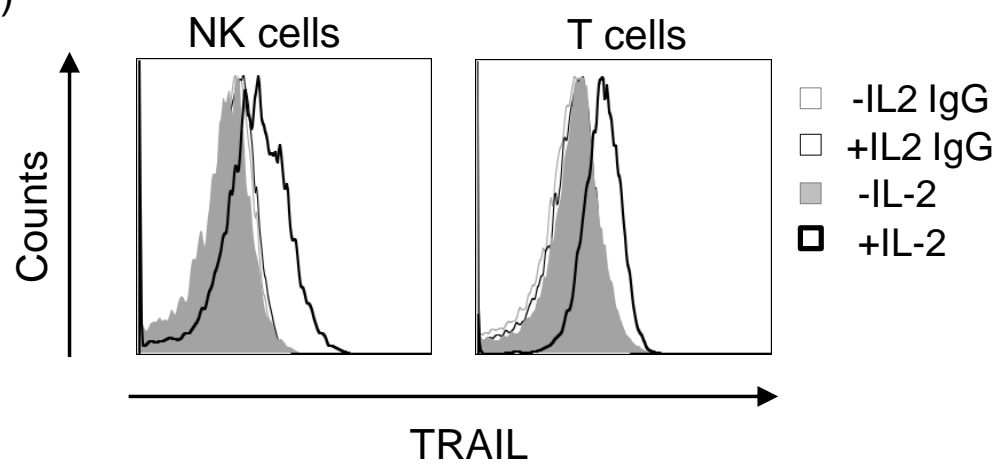

B)

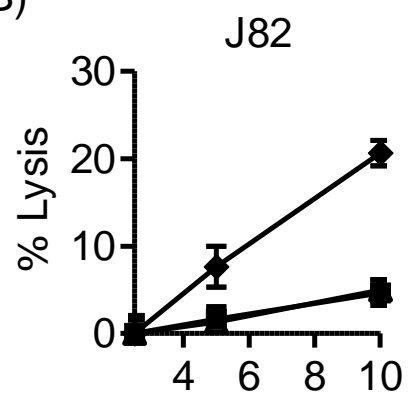

ET:ratio

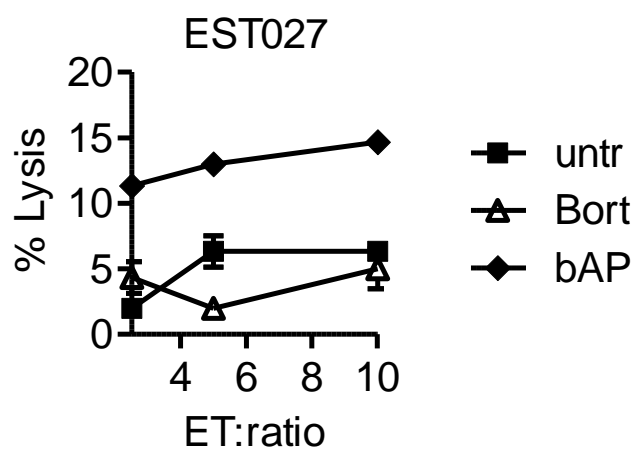

C)

NK cells

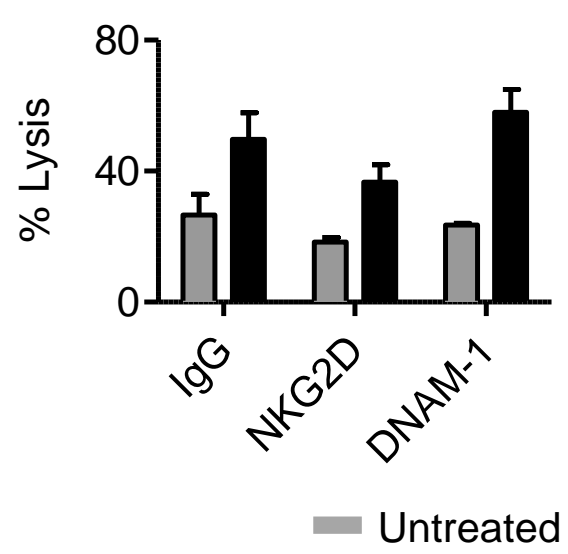

T cells

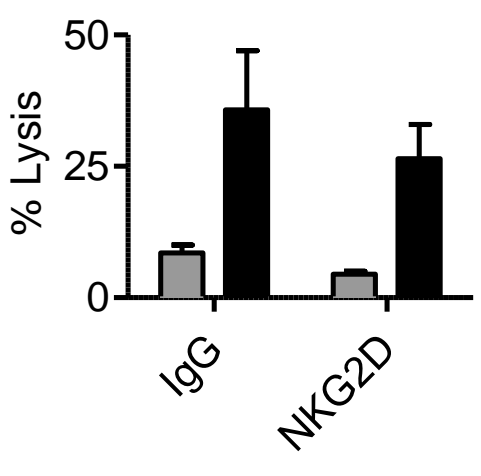

b-AP15

A) Flow cytometry analysis of TRAIL expression on NK- and T-cells in presence or absence of [500 $\mathrm{U} / \mathrm{ml}$ IL-2 for four days. One of two independent experiments with similar results is shown. B) J82 and EST027 cells were either treated with b-AP15 [1 uM, 3 hours], bortezomib [Bort; $20 \mathrm{nM}, 20$ hours] or left untreated and tested in an in vitro 18 hour $51 \mathrm{Cr}$-release assay for killing by Mart-1 specific T cells. C) J82 cells were treated with b-AP15 [1 uM, 3hours] and tested in an in vitro 18 hour $51 \mathrm{Cr}$-release assay for killing by NK cells in presence of neutralizing antibodies to NKG2D or DNAM-1 or T cells in presence of neutralizing antibodies to NKG2D. 
Cancer Immunology, Immunotherapy (submitted in 2013) - Dhifaf Sarhan et al.

A)

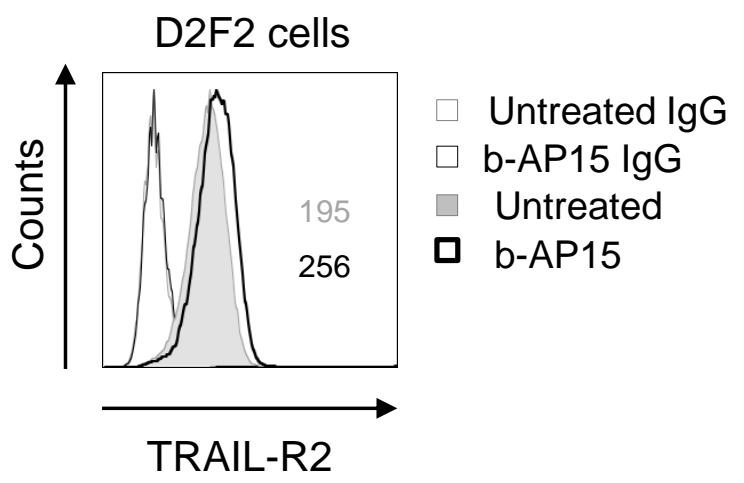

B)

D2F2

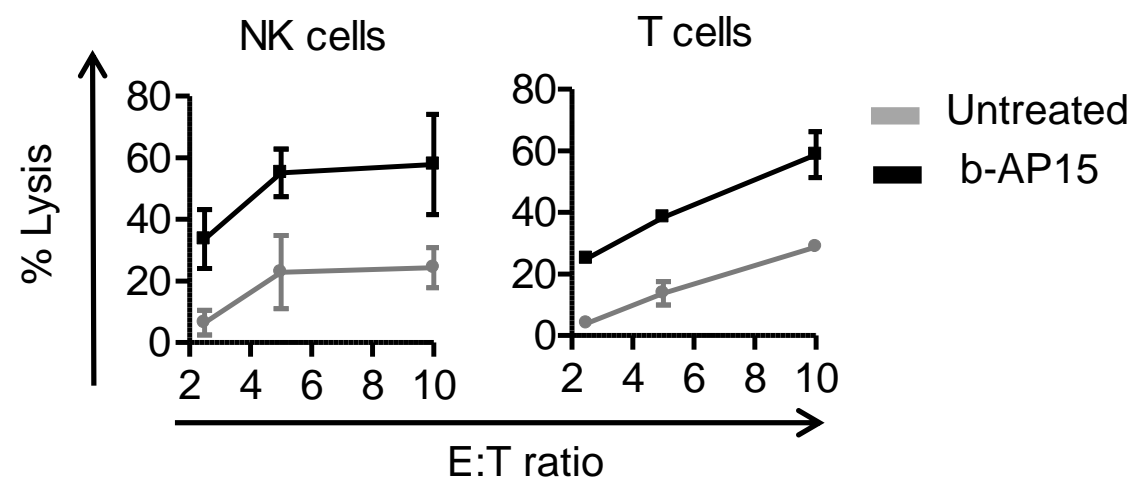

C)
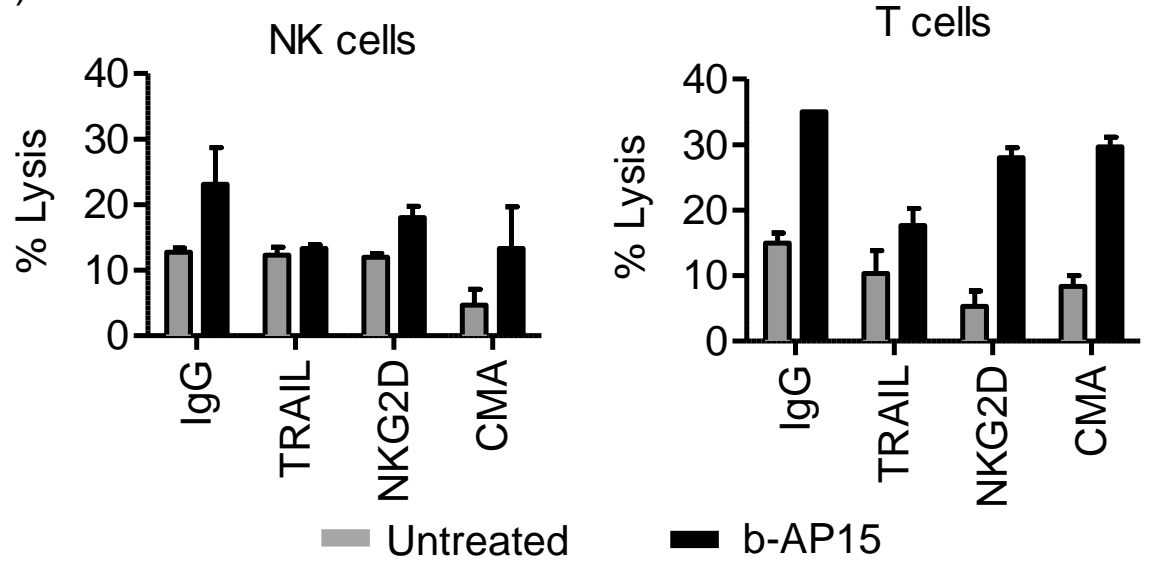

A) Flow cytometry analysis of TRAIL-R2 expression in untreated and b-AP15 treated [1 $\mathrm{uM}, 3$ hours] D2F2 cells. Values in graph represent MFI-values of TRAIL-R2 staining. B) Murine BALB/c NK cells or D2F2-specific T cells were tested against untreated and b-AP15 treated [1 uM, 3 hours] D2F2 tumor cells in an 18 hour 51 Cr-release assay $(n=3)$. C) D2F2 cells were treated with b-AP15 [1 uM, 3 hours] and tested in an in vitro 18 hour $51 \mathrm{Cr}$-release assay for killing by NK or T cells in presence of neutralizing antibodies to TRAIL, NKG2D or in presence of Concanamycin A (CMA). 